\title{
Erratum: Retrieving Ideal Precision in Noisy Quantum Optical Metrology [Phys. Rev. Lett. 123, 040402 (2019)]
}

Kai Bai, Zhen Peng, Hong-Gang Luo, and Jun-Hong An®

(ब) (Received 11 August 2021; published 16 September 2021)

DOI: 10.1103/PhysRevLett.127.129902

In our original Letter, the labels for the two lines in the inset of Fig. 1(b) were accidentally interchanged. The correct form of Figs. 1(b) and 1(c) is as follows.

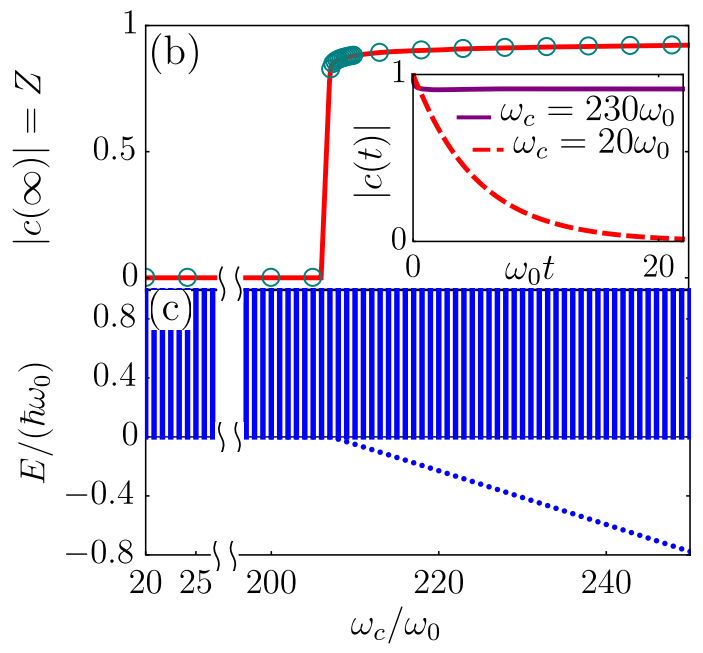

FIG. 1. 